\title{
Learning From the Pandemic: The Impacts of Moving Student-Staff Partnerships Online
}

\author{
Madelaine-Marie Judd \\ The University of Queensland, Australia \\ Franciele Spinelli \\ The University of Queensland, Australia \\ Brooke Szucs \\ The University of Queensland, Australia \\ Naima Crisp \\ The University of Queensland, Australia \\ Julia Groening \\ The University of Queensland, Australia \\ Christy Collis \\ University of Southern Queensland, Australia \\ Beata Batorowicz \\ University of Southern Queensland, Australia \\ Dino Willox \\ The University of Queensland, Australia \\ Anna Richards \\ The University of Queensland, Australia
}

\begin{abstract}
While numerous studies on the impacts of COVID-19 on university learning and teaching are now emerging, there has been less critical attention focused on the impact of the shift to online engagement on student-staff partnership (SSP) practices. This article analyses the experiences and perceptions of students and staff from an Australian university as they shifted their partnership practices online during the pandemic. It provides valuable insights into the specific positive and negative impacts of online SSP for students and staff, foregrounding both groups' perceptions of the accessibility and communication aspects of online SSP. The study's findings lead to the recommendation of a blended approach and will be of use as SSP programs recalibrate for a post-COVID context.
\end{abstract}

Keywords: Student-staff partnership; online engagement; student success.

\section{Introduction}

Over the past 15 years, student-staff partnership (SSP) has been increasingly recognised as a transformational ethos and way of working within higher education (Bovill, 2019; Cook-Sather et al., 2014; Dollinger \& Vanderlelie, 2019; Healey et al., 2016; Kek et al., 2017; Matthews et al., 2018). While there are various definitions of SSP, it has a consistent core ethos: SSP seeks to break down existing power imbalances within higher education and create meaningful spaces for dialogue between students and staff (Matthews et al., 2018; Peseta \& Bell, 2020). This ethos advocates for the "democratisation of the educational process" through providing agency for students to influence and impact decision-making processes that govern their everyday lives in

Except where otherwise noted, content in this journal is licensed under a Creative Commons Attribution 4.0 International Licence. As an open access journal, articles are free to use with proper attribution. ISSN: 2205-0795 
higher education such as the curriculum (Bovill et al., 2016, p.1). In doing so, SSP recognises that both students and staff have uniquely valuable expertise and experiences to contribute to shaping student life in higher education (Cook-Sather et al., 2014; Peseta \& Bell, 2020). This ethos provides a transformational space that fosters mutual learning between students and staff, requiring university communities to rethink and critique previously held assumptions on whose knowledge matters in curriculum design and overall decision-making in higher education.

However, subverting long-standing power structures entrenched within higher education is not without its challenges. Whether it be in the form of resistance to the very ethos or, on a practical level, the significant amount of time required to form the necessary collegial relationships, SSP is a practice and approach that requires effort, understanding, and an open outlook to be fully realised (Cook-Sather et al., 2021; Marquis et al., 2016).

\section{Then There was a Global Pandemic}

Time pressures on both students and staff were exacerbated by the COVID-19 global pandemic (Lyons et al., 2020; Patty, 2020; Slade et al., 2021). Due to physical distancing requirements, many universities were required to shift from on-campus to online delivery; a significant number of students lost casual or part-time employment; and thousands of university staff members across Australia lost jobs or had to take on larger workloads with less support and/or fewer resources (Bao, 2020; Larkin, 2020; Thatcher et al., 2020). The higher education sector was faced with the reality of having to immediately change its delivery model with fewer resources, whilst ensuring that students who were suddenly located remotely could still engage in university education.

\section{Where Does This Leave Student-Staff Partnership?}

Arguably, in light of the new challenges that students and staff faced within higher education, partnership was more important than ever (Judd et al., 2020). In reality, constraints were highlighted by the impact of the global pandemic (Ntem et al., 2020). In an editorial piece by five student journal co-editors (Ntem et al., 2020), a range of challenges of engaging in partnership online were identified. These included a lack of access to reliable internet, increasing time poverty of both students and staff and broader impacts on the process of relationship-building that is vital at the beginning of partnership engagements. Concerns regarding access to partnership and time-poverty were affirmed by McCreadie (2020), and Impastato and Topper (2020), with the latter finding that students and staff "struggled to rebalance and structure our now-isolated lives" (p.1). There is a paucity of literature concerning engaging in partnership online (Ntem et al., 2020). The research reported in this article will contribute to addressing this gap in the literature by analysing the experiences of students and staff who participated in a university-wide SSP program that transitioned online in the wake of the pandemic.

\section{The Present Study}

This study sought to unpack the impacts of the COVID-19 pandemic on the SSP Projects Program at The University of Queensland (UQ), Australia and to develop recommendations to inform and enhance scholarship and practice. Based in Brisbane, UQ has a student population of approximately 55,000 and a staff population of just over 7,000 (The University of Queensland, 2020). Since it was established in 2018, the SSP Projects Program has supported over 1,100 students and over 600 staff $^{1}$ to engage in semester-long projects that seek to enhance the UQ community in the areas of teaching and learning, student experience and governance and strategy.

The research questions guiding this study were:

1. How do students and staff perceive engaging in partnership online?

2. What impacts did the global pandemic have on the accessibility of SSP?

3. What lessons can be learned to enhance SSP practices?

This research has been approved by The University of Queensland Humanities and Social Sciences Ethics Sub-Committee (Approval Number: 2018001275).

\footnotetext{
${ }^{1}$ This refers to the number of unique number of students and staff who have collaborated on SSP Projects.
} 


\section{Methodology}

\section{Design}

The research presented in this article is part of a larger study, which explores the implementation of the UQ SSP Projects Program since 2018. The present study only includes data from participants who engaged in online partnership in 2020.

To investigate the three research questions, the present study was informed by a mixed-methods approach drawing on survey, focus group and interview data of students and staff who participated in SSP Projects at UQ in 2020. Via targeted email, Student and Staff Partners were invited to participate in the study through completing a post-project survey and/or participating in a one-hour semi-structured interview/focus group.

\section{Participants}

In total, this study incorporated the perspectives of 28 students (23 survey respondents and 5 interview/focus group participants) and 28 staff members (22 survey respondents and 6 interview/focus group participants). Student participants were from a wider range of disciplines than staff participants, as illustrated in Table 1. Of the student participants, approximately 57\% identified as female, $32 \%$ as male and the remainder did not disclose their gender. This contrasted to the staff participants, with $71 \%$ identifying as female, $25 \%$ as male, and $4 \%$ preferring not to disclose.

\section{Table 1}

Number of Student and Staff Participants by Faculty/Division

\begin{tabular}{|l|c|c|c|c|c|c|c|}
\hline & $\begin{array}{c}\text { Central } \\
\text { Division }\end{array}$ & $\begin{array}{c}\text { BEL } \\
\text { Faculty }\end{array}$ & $\begin{array}{c}\text { EAIT } \\
\text { Faculty }\end{array}$ & $\begin{array}{c}\text { HABS } \\
\text { Faculty }\end{array}$ & $\begin{array}{c}\text { HASS } \\
\text { Faculty }\end{array}$ & $\begin{array}{c}\text { Medicine } \\
\text { Faculty }\end{array}$ & $\begin{array}{c}\text { Science } \\
\text { Faculty }\end{array}$ \\
\hline Students & 0 & 5 & 5 & 3 & 7 & 2 & 5 \\
\hline Staff & 4 & 2 & 0 & 3 & 13 & 5 & 1 \\
\hline
\end{tabular}

Notes: BEL = Business, Economics and Law; EAIT = Engineering, Architecture and Information Technology; HABS = Health and Behavioural Sciences; HASS = Humanities and Social Sciences

Of the student participants, $57 \%$ were domestic, and 32\% international, with the remainder not responding to this question. Approximately $61 \%$ were undergraduate and $29 \%$ coursework postgraduate students. ${ }^{2}$ Of the staff participants, there was equal representation of academic and professional staff, with 13 of the 28 staff participants having worked at the University for more than seven years. For the purposes of this study, the term "Staff Partners" includes both academic and professional staff members.

\section{Study Tools}

Online surveys and interview/focus groups were implemented in this study. The research design was grounded in Bovill's (2017) theoretic approach to Students as Partners. The three main propositions influencing the survey question selection and wording were: 1) the creation and continual care to maintain reciprocal relationships; 2) skepticism from students about the degree to which staff engage in partnership; and 3) exploring partners' motivations for engaging in partnership and their underpinning values.

\footnotetext{
${ }^{2}$ These figures do not include three participants who did not respond to the demographic question related to their studies profile.
} 
The online survey consisted of multiple choice (14 multiple choice questions for staff and 15 for students), open-ended (6 openended questions for both staff and students) and Likert-type scale questions ( 1 for staff and 2 for students) all of which explored participants' experiences of SSP Projects. Drawing on a previous study exploring student and staff members perceptions of engaging in partnership (Coombe et. al., 2018), separate surveys were created for students (23 questions) and staff (21 questions), with two questions only being relevant to students. Survey questions included those related to: respondents' involvement in the SSP Program, including whether online, face-to-face or dual mode; motivations for engaging in partnership; describing what partnership means to them; the challenges involved in engaging in partnership; and how partners overcame these challenges.

Similarly, separate interviews/focus groups were facilitated for staff and students to ensure the relevance of questions and that participants felt comfortable disclosing their perspectives with a similar cohort. All interviews/focus groups were facilitated by a member of the authorship team online via Zoom, audio recorded and transcribed. Each interview/focus group was one-hour in duration and consisted of nine and ten questions for students and staff, respectively. Interviews/focus groups sought to explore participants' experiences of engaging in partnership, along with their perceptions of the broader impacts of engaging in partnership. Questions included how decisions were made within the partnership team, the challenges that partners faced and motivations to become a partner. The number of participants in each interview/focus group ranged from one to three.

\section{Mixed-Methods Approach}

An independent, manual, thematic sentiment analysis of the survey and interviews/focus group was undertaken by two members of the authorship team, drawing on the analysis of previous studies in the field (Kinash et al., 2015; Zacharias \& Mitchell, 2020). Only data that explicitly referred to engaging in SSP online was included in the analysis, with data analysed in light of positive, neutral or negative sentiment and themes that were mutually agreed upon by two members of the authorship team. A third member of the authorship team reviewed the analyses to ensure the sentiment and theming of quotes was consistent, and to minimise the risks of subjectivity (Kinash et al., 2015; Shaddock \& Hattie, 2014).

\section{Results}

\section{Sentiment Analysis}

As seen in Figure 1, when discussing online partnership in the surveys and interviews/focus groups, almost half of the student and staff participants expressed a negative sentiment. Notably, a greater number of student quotes were positive compared to staff quotes, with the authors noting in their analyses that Staff Partner sentiment was overall less emotive and more descriptive than Student Partners.

\section{Figure 1}

Number of Sentiment Coded Quotes by Students/Staff
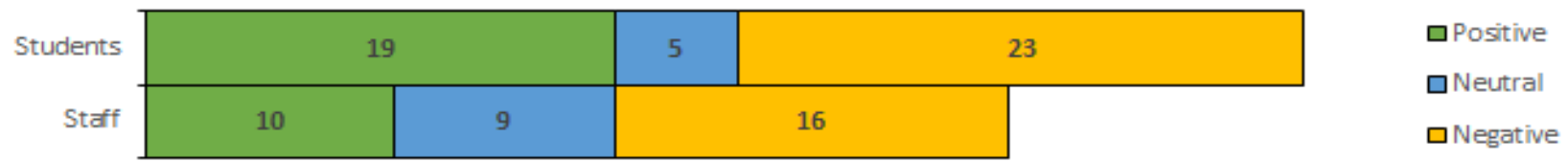

\section{Thematic Analysis}

A thematic analysis allowed for a deeper exploration of the sentiment results, to understand differences and similarities between student and staff perspectives of engaging in online partnership. When examining the student and staff interviews/focus groups and survey results, seven themes emerged: communication, social, accessibility, platform, time poverty, learning and outcomes. These are explored in further detail below, accompanied by their sentiment results in Figure 2. 


\section{Figure 2}

Number of Sentiment Coded Quotes by Theme and Students/Staff

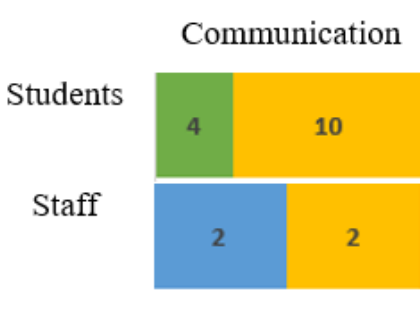

Time Poverty

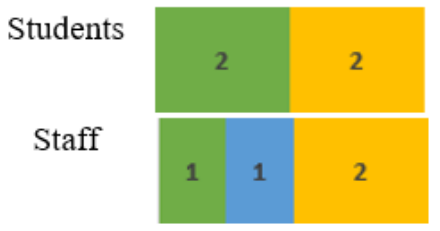

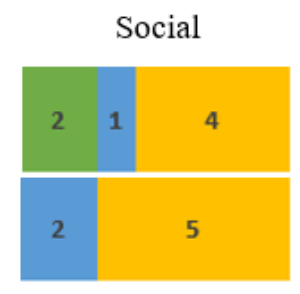

Learning

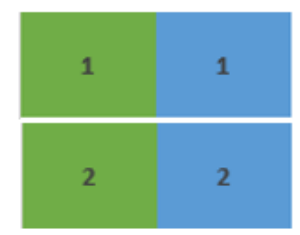

Accessibility

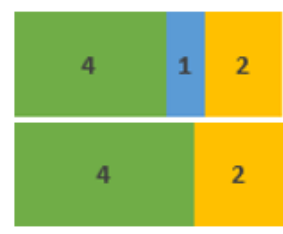

Outcomes

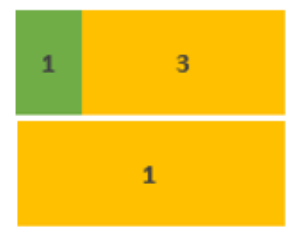

Platform



Positive

Neutral

Negative

\section{Communication}

Communication refers to the impacts of online partnership on collaboration and communication between partners. As shown in Figure 2, this was a primary theme among student participants, with the majority expressing negative sentiment $(n=10)$. Staff and students responded that they struggled to communicate entirely online, with student participants citing long wait times for email responses, and barriers to social connection normally possible through body language and nuance. As one student explained:

I feel that online communication really lacks the person, like person-to-person, because person-to-person you can pick up on the body language, and get like point to things on pieces of paper, and you can actually discuss it openly. Whereas online you just have to tag it, like you can't put really any emotion into things. (Student Partner, Focus Group)

In some cases, the onset of the pandemic seemed to cause a communication breakdown within the team, putting their project on hold. A student commented, "We were going so well at the start ... and then everything shut down and it felt like the whole project shut down as well" (Student Partner, Focus Group).

Positive sentiment on the theme of communication focused on the convenience of connecting online, with a Student Partner commenting on the ease of brief online check-ins.

\section{Social}

This theme focuses on the broader impacts of forming and developing social connections within partnership teams when engaging online. When discussing the ways in which the online environment affected Student and Staff Partners, the majority of participants ( $n=4$ students and $n=5$ staff) highlighted the negative impacts that the pandemic had on their ability to build social connections and rapport as a group, especially compared to their previous face-to-face partnership experiences. One participant noted:

Personally, I thought that having all the meetings virtually was a challenge ... I feel like if we were able to have face-to-face meetings, I would have been able to build more valuable relationships with the other partners and the professor. (Student Partner, Survey)

Participants also expressed difficulties in discussing challenging topics and situations online. "Tricky negotiations are better face-to-face. I'm not sure why but there's a little bit more humanity in being able to use body language and so on" (Staff Partner, Focus Group). 


\section{Accessibility}

Accessibility refers to the impacts that online partnership had on the flexibility of engagement, and inclusion of students from diverse backgrounds and geographical locations, including those living overseas.

As illustrated in Figure 2, a greater number of staff members who talked about this theme felt that online partnership had a positive impact on accessibility. This was particularly evident for partners who may not have been able to participate in the program under normal circumstances:

[Previously at the] induction ... everybody had to turn up face-to-face and that's actually a barrier because we're a very distributed program and we have four rural clinical schools and so actually that's been better with the online because really it was a bit St Lucia centric. (Staff Partner, Focus Group)

Both student and staff participants also spoke of the ease in scheduling meetings and not having to commute to campus: "I really liked the flexibility of the online environment. I live about an hour and a half away from campus via public transport, and I found it a lot easier to arrange meetings virtually" (Student Partner, Focus Group).

Negative sentiment on this theme centered on poor internet connection or lack of access to necessary equipment or software to fully participate online. As one student explained, "There is definitely the issue of internet connection ... and if we don't have it then the whole meeting goes down the drain" (Student Partner, Focus Group). This was further exacerbated if one of the partners did not have a proper device and/or lacked a camera in their computers, preventing them from participating in the same way as their team members. As a staff member explained, "One of my current Student Partners, for them they don't have cameras, so they are the only one that isn't on the screen" (Staff Partner, Interview).

\section{Platforms}

This theme focuses on the experiences and perspectives of partners utilising online collaboration tools. While staff and students noted similar experiences of collaborating and communicating via online platforms, staff sentiment was slightly more negative $(n=4)$, with "Zoom fatigue" impacting on their experiences. One staff member described it thus, "I in particular, have had virtual fatigue, just with the whole semester. So many Zooms and so many workshops and everything like that. It would have been really refreshing to brainstorm face-to-face" (Staff Partner, Focus Group). Similarly, staff expressed negative sentiment about the difficulty in maintaining professional boundaries, depending on the platform chosen for communication. A Staff Partner commented in a focus group:

We communicated through Facebook, that was our communication hub. I would prefer Zoom Chat, not a huge fan of talking to students on Facebook. So I struggled with that ... I'm like 'yeah but that's my life and this is work'.

Students, however, solely expressed positive sentiment regarding online platforms, acknowledging the convenience that enabled them to collaborate flexibly from home, with one student viewing it as a means to escape social isolation. Students also noted the efficiency of online platforms for different project tasks, including the ease in taking notes during virtual team meetings:

It's also very helpful to create documents, so in this meeting we had we were working with Google Docs and each one of us was typing a little bit onto the document and then it was ready by the time we finished the meeting. (Student Partner, Focus Group)

\section{Time Poverty}

Time poverty is related to the conflicting schedules and time constraints that participants expressed in moving online. Both students and staff reported the positive and negative impacts in relation to their availability to engage online. Positive sentiment centered on the flexibility of online platforms, and the elimination of transiting time to campus, thus enabling both staff and students to complete other tasks. As one student explained:

I think that doing it online is fantastic because it's very easy to book the meetings and we don't have to worry about the commute, and then parking the car or waiting for the bus, and that takes time. And it's time that we could be spending doing something else, doing the project for example. (Student Partner, Interview) 
For many staff, however, negative sentiment centered on mounting commitments outside of the partnership. As one Staff Partner explained, "There simply was not the time nor capacity this semester to foster learning environments for the SSP team" (Staff Partner, Survey).

\section{Learning}

This theme specifically refers to the capabilities and knowledge that partners attained in adapting to online partnership. Although some participants ( $n=1$ student and $n=2$ staff) described learning in descriptive, non-emotive terms, others $(n=1$ student and $n=2$ staff) spoke of the positive value of learning to navigate online partnerships. A staff participant noted that engaging in partnership online provided an opportunity to participate in virtual meetings for the very first time, noting, "I had to learn how to do Zoom to do my induction training for SSP, so that's my first exposure to Zoom” (Staff Partner, Focus Group).

Another Staff Partner noted that they developed a better understanding of how students were affected by the transition to online learning, stating, "It was interesting to undertake this project in the midst of a pandemic but gave me insight into how online learning really affects the student experience" (Staff Partner, Survey).

\section{Outcomes}

This theme focuses on the impacts that the pandemic and engaging online had on the project goals. Student sentiment was primarily negative ( $n=3$ students and $n=1$ staff), with students indicating that they had to change their intended outcomes to accommodate the new reality. This included changing the desired roles of partners and downsizing the project due to new constraints. One participant, however, expressed positive sentiment regarding the impact of moving online to their final outcomes, commenting that, "the finished product was sort of better than what he had originally thought of" (Student Partner, Focus Group).

This theme was only mentioned once by staff, who noted that students could no longer be as active in their partnership due to the move to online teaching, "The biggest challenge was the change of timetable and moving classes to online meant rethinking our project data collection and [the move] possibly impacted this greatly" (Staff Partner, Survey).

\section{Discussion}

This study sought to explore and reflect upon the impacts that engaging online had on SSP practices through drawing upon the perspectives of Student and Staff Partners that moved their collaborations online in the wake of the pandemic. The findings related to each of the research questions are outlined below.

\section{(RQ1) How do students and staff perceive engaging in partnership online?}

The results of the present study revealed that students and staff recognised the positive and negative impacts of engaging in partnership online. When examining the negative impacts, students primarily focused upon the lack of social connections and communication difficulties associated with engaging in partnership online. This perceived loss of social engagement had a negative impact on the important work of relationship-building and was also evidenced within the broader Teaching and Learning environment (Redmond et al., 2018; Zapata-Cuervo et al., 2021). Similarly, staff expressed discontent with the lack of face-to-face contact, but their primary concerns focused on identifying and getting the most out of online collaboration platforms to enable authentic partnership. These findings are congruent with the findings of McCreadie (2020) and Ntem et al. (2020) who identified the impacts of loss of social connection and communication challenges associated with engaging in partnership online.

When examining the impacts, students were generally more positive than staff, and in particular focused on the benefits of the flexibility of online partnerships and online platforms. In broader reflection, the positive student and staff responses from the present study offer valuable insights into how partnership can serve as a vital ethos to combat social isolation and ensure that students and staff maintain a sense of belonging and wellbeing in the context of physical distancing restrictions.

(RQ2) What impacts did the global pandemic have on the accessibility of SSP Projects?

One of the primary findings of this research was the perceived (and experienced) impact of collaborating online to enable greater accessibility of partnership activities to students and staff. 
For students, this was perceived with mainly positive sentiment, primarily in relation to the savings in time, money, and effort required to commute to campus. Staff also acknowledged these benefits and expressed the ease of convenience of online platforms. This key finding was also reflected within the literature, with McCreadie (2020) and Ntem et al. (2020) noting the potential for online engagement to reduce barriers for students and staff to collaborate with one another in partnership. This finding aligns with student and staff responses more broadly to the pandemic-related shift to online learning. Although equity issues related to internet and technology quality have been amplified in the completely online environment (Mupenzi et al., 2020; Zapata-Cuervo et al., 2021), the time and cost savings associated with the elimination of travel time to physical campuses have been viewed positively by students and staff alike (Ali, 2020).

\section{(RQ3) What lessons can be learned to enhance SSP practices?}

Three overall recommendations to guide and enhance practice are derived from the literature and the key findings of this study.

(1) Offer opportunities to engage in partnership in dual-mode (online and on campus).

Participants in this study identified that whilst engaging in online partnership increased inclusion, accessibility and flexibility of partnership activities, it also had the potential to stymie social connections between partners. These concerns were also reflected within the literature (McCreadie, 2020; Ntem et al., 2020). To address this challenge posed by online engagement, a recommendation is to provide opportunities for partners to collaborate in dual-mode, where possible, to ensure flexibility whilst enabling the development of connectivity. Hosting more socially-focused SSP activities on campus while conducting most of the 'work' of SSP online would address staff and student concerns with the loss of social engagement and connection while retaining the efficiencies that both students and staff associate with working online. However, a blended approach may not be possible in many places where the pandemic continues to prevent on-campus activity, either entirely or through unplanned, limited-period lockdowns.

(2) Offer social events and opportunities for partners to connect.

Providing opportunities for Student and Staff Partners to connect, online and in person, enables teams to seek support, whilst also developing rapport and trust. This may be via the development of a community of practice or other types of informal support networks (Wang \& DeLaquil, 2020). Such networks establish an environment whereby students and staff get to know one another on a "human level". The value of taking the time to develop trust was identified by Impastato \& Topper (2020) and Ntem et al. (2020) as of critical importance to fostering and sustaining positive partnership experiences. While approaches to building social activities for developing rapport and trust in SSP are well known and well researched, understandings of online approaches are currently limited. The pandemic has generated substantial evidence as to the efficacy of various approaches to online engagement in educational contexts (for example, Tualaulelei et al., 2021); online SSP programs can draw from this evidence base in order to sustain the social engagement which students and staff identify as critically important to the values and ethos of SSP.

(3) Agree upon suitable guidelines for collaborating online.

In this study, staff and students alike commented on the challenges of communicating and collaborating online. Whether it be through the blurring of professional and personal boundaries through the use of platforms such as Facebook, Zoom fatigue, or a lack of opportunities for direct and instant communication as a team, these challenges reflected the general experiences within the higher education sector as a result of the pandemic (Nadler, 2020; Wang \& DeLaquil, 2020; Williams, 2021). A recommendation offered by participants was to provide opportunities at the beginning of the engagement for open and honest conversations regarding suitable platforms to collaborate on to ensure ease of communication, whilst protecting partners' privacy.

\section{Conclusion}

The impacts of COVID on university programs has been profound: it has presented significant challenges, but also opened up opportunities for experimenting with alternative modes of practice. Partnership programs, such as the one that is the focus of this article, have had to recalibrate in order to retain the transformational value of SSP in a radically changing university environment. This article has provided evidence about the impact of the shift of one SSP program online, attending to the experiences and perceptions of both staff and students involved in this program. While the present study has a reasonably small sample size ( $n=28$ students, $n=28$ staff) which may limit the generalisability of the results, the study has generated productive insights into online SSP by identifying strong thematic strands in both staff and student data. The increased accessibility of the 
SSP program emerged as a significant positive feature for students. This element of online SSP programs may be an approach that could be retained into the future to enhance these programs' accessibility to diverse students. Social connection and communication between students and staff, on the other hand, was perceived as negatively impacted by the shift online, both in terms of a sense of shared social engagement, and, for staff particularly, in terms of professional boundary-setting.

This article is thus neither a wholesale celebration of online SSP, nor is it a rejection of it. Rather, this article has unpacked the complex dynamics of SSP itself, identifying ways in which online SSP facilitates some strands of engagement, and in which it may impede others. Partnership is important. Understanding the ways in which the affordances of both online and on-campus engagement can enhance and sustain SSP is critical to its ongoing development and success. As is often the case, there is no clear 'formula' for a successful SSP program. However, this article's focus on the COVID-triggered shift to online SSP has provided valuable insights into ways in which online engagement can either improve or impede SSP programs. These insights will be vital as SSP programs recalibrate themselves for a post-COVID context.

\section{Acknowledgements}

The authors would like to acknowledge the SSP Community at UQ, and specifically those who participated in this study. We would also like to acknowledge Associate Professor Kelly Matthews for her scholarly leadership in SaP, and other sector leaders such as Professor Sally Varnham, Professor Mick Healey, Dr Tai Peseta, Dr Cathy Bovill, Dr Amani Bell and Dr Mollie Dollinger for their scholarly contributions which continue to shape our perceptions of partnership. 


\section{References}

Ali, W. (2020). Online and remote learning in higher education institutes: A necessity in light of the COVID-19 Pandemic. Higher Education Studies, 10(3), 16-25. https://doi.org/10.5539/hes.v10n3p16

Bao, W. (2020). COVID-19 and online teaching in higher education: A case study of Peking University. Human Behavior and Emerging Technologies, 2(2), 113-115. https://doi.org/10.1002/hbe2.191

Bovill, C. (2017). A framework to explore roles within student-staff partnerships in higher education: Which students are partners, when, and in what ways? International Journal for Students as Partners, 1(1), 1-5. https://doi.org/10.15173/ijsap.v1i1.3062

Bovill, C. (2019). Student-staff partnerships in learning and teaching: An overview of current practice and discourse. Journal of Geography in Higher Education, 43(4), 385-398. https://doi.org/10.1080/03098265.2019.1660628

Bovill, C., Cook-Sather, A., Felten, P., Millard, L., \& Moore-Cherry, N. (2016). Addressing potential challenges in cocreating learning and teaching: Overcoming resistance, navigating institutional norms and ensuring inclusivity in studentstaff partnerships. Higher Education, 71, 195-208. https://doi.org/10.1007/s10734-015-9896-4

Cook-Sather, A., Bovill, C., \& Felten, P. (2014). Engaging students as partners in learning and teaching: A guide for faculty $\left(1^{\text {st }}\right.$ ed.). Jossey-Bass.

Cook-Sather, A., Slates, S., Acai, A., Baxter, J., Bond, R., Lowe, T., Zurcher, H., O’Brien, J., Tavares, V., Lewe, M.-T., Khan, A., Poole, H., Smith, A. C., Iqbal, M. Z., Arm, K., Escobar Lema, J. E. ., Groening, J., Garg, K., Bello Rinaudo, N. L., Crisp, N., Mukherji, M. ., Addy, T., Lewis, L. M., Vayada, P., Zhang, M., Liang, Y. (Scott) ., Rodgers, H. B., Judd, M.-M. ., Szucs, B., Thompson, D., Schmidt, S. ., Semos, I., Watchman Smith, N., Pfeifer-Luckett, R. ., Bala, N., Chia, M.-D., Kochhar-Lindgren, G. ., Leung, L. ., Lys, I., Matthews, K., Zou, T., \& Lewis, R. (2021). Diversifying students-aspartners participants and practices. International Journal for Students as Partners, 5(1), 146-159. https://doi.org/10.15173/ijsap.v5i1.4627

Coombe, L., Huang, J., Russell, S., Sheppard, K., \& Khosravi, H. (2018). Students as partners in action: Evaluating a university-wide initiative. International Journal for Students as Partners, 2(2), 85-95. https://doi.org/10.15173/ijsap.v2i2.3576

Dollinger, M., \& Vanderlelie, J. (2019). Developing and enacting student governance and leadership training in higher education. Student Success, 10(2), 59-64. https://doi.org/10.5204/ssj.v10i2.1309

Healey, M., Flint, A., \& Harrington, K. (2016). Students as partners: Reflections on a conceptual model. Teaching and Learning Inquiry, 4(2), 1-13. https://doi.org/10.20343/10.20343/teachlearninqu.4.2.3

Impastato, J., \& Topper, L. (2020). Support systems and transgressive hierarchies: Insights we gained through the transition online while planning for pedagogical partnership. Teaching and Learning Together in Higher Education, 30(1). https://repository.brynmawr.edu/tlthe/

Judd, M-M., Crisp, N., Groening, J., \& Spinelli, F. (2020, November 15). Keeping student-staff partnership alive. Campus Morning Mail. https://campusmorningmail.com.au/news/keeping-student-staff-partnerships-alive/

Kek, M., Kimmins, L., Lawrence, J., Lindgren, C., \& Stokes, T. (2017). Students enabling students in a student partnership project: A case study emerging from the OLT transforming practice project on Student Partnerships. Student Success, 8(2), 117-122. https://doi.org/10.5204/ssj.v8i2.389

Kinash, S., Crane, L., Judd, M-M., Knight, C. \& Dowling, D. (2015, July 6-9) What students and graduates need to know about graduate employability: Lessons from national OLT research [Conference paper]. In T. Thomas, E. Levin, P. Dawson, K. Fraser \& R. Hadgraft (Eds.), Research and Development in Higher Education: Learning for Life and Work in a Complex World, 38 (pp 94-106). Melbourne, Australia.

Larkin, M. (2020, June 16). University students who work part-time need support - or they will drop out. The Guardian. https://www.theguardian.com/education/2020/jun/16/university-students-who-work-part-time-need-support-or-they-willdrop-out

Lyons, Z., Wilcox, H., Leung, L., \& Dearsley, O. (2020). COVID-19 and the mental well-being of Australian medical students: Impact, concerns and coping strategies used. Australasian Psychiatry, 28(6), 649-652. https://doi.org/10.1177/1039856220947945

McCreadie, C.R. (2020). Learner-teacher partnership in times of COVID-19: Community poll review. International Journal for Students as Partners, 4(2), 155-157. https://doi.org/10.15173/ijsap.v4i2.4371

Marquis, E., Black, C., \& Healey, M. (2017). Responding to the challenges of student-staff partnership: The reflections of participants at an international summer institute. Teaching in Higher Education, 22(6), 720-735. https://doi.org/10.1080/13562517.2017.1289510

Matthews, K.E., Cook-Sather, A., Acai, A., D., Sam, L., Felten, P., Marquis, E., \& Mercer-Mapstone, L. (2018). Toward theories of partnership praxis: An analysis of interpretive framing in literature on students as partners in teaching and learning. Higher Education Research and Development, 38(2), 280-293. https://doi.org/10.1080/07294360.2018.1530199 
Mupenzi, A., Mude, W., \& Baker, S. (2020). Reflections on COVID-19 and impacts on equitable participation: The case of culturally and linguistically diverse migrant and/or refugee (CALDM/R) students in Australian higher education. Higher Education Research and Development, 39(7), 1337-1341. https://doi.org/10.1080/07294360.2020.1824991

Nadler, R. (2020). Understanding "zoom fatigue": Theorizing spatial dynamics as third skins in computer-mediated communication. Computers and Composition, 58, 102613. https://doi.org/10.1016/j.compcom.2020.102613

Ntem, A., Nguyen, E., Rafferty, C., Kwan, C., \& Benlahcene, A. (2020). Students as partners in crisis? Student co-editors' perspectives on COVID-19, values, and the shift to virtual spaces. International Journal for Students as Partners, 4(2), 18. https://doi.org/10.15173/ijsap.v4i2.4432

Patty, A. (2020, March 5). Coronavirus puts heat on uni staff to quickly produce online courses. The Sydney Morning Herald. https://www.smh.com.au/national/coronavirus-puts-heat-on-uni-staff-to-quickly-produce-online-courses-20200303p546fi.html

Peseta, T., \& Bell, A. (2020). Seeing institutionally: A rationale for 'teach the university' in student and staff partnerships. Higher Education Research and Development, 39(1), 99-112. https://doi.org/10.1080/07294360.2019.1676200

Redmond, P., Heffernan, A., Abawi, L., Brown, A., \& Henderson, R. (2018). An online engagement framework for higher education. Online Learning, 22(1), 183-204. https://doi.org/10.24059/olj.v22i1.1175

Shaddock, A., \& Hattie, J. (2014). Using data to improve learning: A practical guide for busy teachers. Australian Council for Educational Research.

Slade, C., Lawrie, G., Taptamat, N., Browne, E., Sheppard, K., \& Matthews, K.E. (2021). Insights into how academics reframed their assessment during a pandemic: Disciplinary variation and assessment as afterthought. Assessment and Evaluation in Higher Education, 1-18. https://doi.org/10.1080/02602938.2021.1933379

Thatcher, A., Zhang, M., Todoroski, H., Chau, A., Wang, J., \& Liang, G. (2020). Predicting the impact of COVID-19 on Australian universities. Journal of Risk and Financial Management, 13(9), 188. https://doi.org/10.3390/jrfm13090188

The University of Queensland. (2020). UQ Fast Facts. https://about.uq.edu.au/fastfacts\#: :text=UQ\%20fast $\% 20$ facts $\% 20 \% 20 \% 20$ Name $\% 20 \% 20, \% 20 \% 24452.5 \% 20$ million $\% 20 \% 2027 \% 20 \mathrm{more} \% 20 \mathrm{rows}$ $\% 20$

Tualaulelei, E., Burke, K., \& Fanshawe, M. (2021). Mapping pedagogical touchpoints: Exploring online student engagement and course design. Active Learning in Higher Education. 1-15. https://doi.org/10.1177/1469787421990847

Wang, L., \& DeLaquil, T. (2020). The isolation of doctoral education in the times of COVID-19: Recommendations for building relationships within person-environment theory. Higher Education Research and Development, 39(7), 13461350. https://doi.org/10.1080/07294360.2020.1823326

Williams, N. (2021). Working through COVID-19: 'zoom' gloom and 'zoom' fatigue. Occupational Medicine, $71(3), 164$. https://doi.org/10.1093/occmed/kqab041

Zacharias, N., \& Mitchell, G. (2020). The importance of highly engaged school-university partnerships in widening participation outreach. Student Success, 11(1), 35-45. https://doi.org/10.5204/ssj.v11i1.1458

Zapata-Cuervo, N., Montes-Guerra, M.I., Shin, Hyejo, H., Jeong, M., \& Cho, M-H. (2021). Students' Psychological perceptions toward online learning engagement and outcomes during the covid-19 pandemic: A comparative analysis of students in three different countries. Journal of Hospitality \& Tourism Education.

https://doi.org/10.1080/10963758.2021.1907195

\section{Please cite this article as:}

Judd, M-M., Spinelli, F., Szucs, B., Crisp, N., Groening, J., Collis, C., Batorowicz, B., Willox, D., \& Richards, A. (2021). Learning from the pandemic: The impacts of moving student-staff partnerships online. Student Success, 12(3), 73-83. https://doi.org/10.5204/ssj.1774

This article has been accepted for publication in Student Success. Please see the Editorial Policies under the 'About' section of the Journal website for further information.

Except where otherwise noted, content in this journal is licensed under a Creative Commons Attribution 4.0 International Licence. As an open access journal, articles are free to use with proper attribution. ISSN: 2205-0795 